\title{
EFFECTIVENESS OF VAGINAL CONE THERAPY ON URINARY INCONTINENCE AMONG WOMEN IN SAVEETHA MEDICAL COLLEGE HOSPITAL, THANDALAM, CHENNAI
}

\author{
JAGADEESWARI J*, KALABARATHI S, MANGALAGOWRI P \\ Department of Nursing, Saveetha College of Nursing, SIMATS, Thandalam, Chennai, Tamil Nadu, India. Email: j.jagadeeswari@gmail.com
}

Received: 12 July 2018, Revised and Accepted: 03 October 2018

ABSTRACT

Objectives: The present aims to assess the level of urinary incontinence in experimental and control group, to assess the effectiveness of vaginal cone therapy on urinary incontinence in experimental group and control group and to associate the post-test level of urinary incontinence with the selected demographic variables among women in the experimental group.

Methods: A quantitative quasi-experimental research design was conducted among 60 women with urinary incontinence. Convenience sampling technique was used. Semi-structured interview method was used to collect the demographical data and level of urinary incontinence among women was assessed by urinary incontinence diagnosis questionnaire.

Results: Among 60 samples in experimental group 26 women had a moderate level of urinary incontinence, and 4 women had slight urinary incontinence whereas in control group 24 women had moderate level of urinary incontinence and 6 women had slight urinary incontinence. The study results show significant improvement in level of urinary incontinence among experimental group than the control group after the intervention at the level of $\mathrm{p}<0.05$. This reveals that vaginal cone therapy is highly significant in the experimental group because pelvic muscle strength had improved and allows the patient to increase the physiological consciousness and promotes the muscle tone after the use of a vaginal cone.

Conclusion: This study proves that vaginal cone therapy is the effective non-pharmacological method, cost-effective method and had no side effects which can be used to treat female urinary incontinence.

Keywords: Vaginal cone therapy, Women, Urinary incontinence.

(C) 2019 The Authors. Published by Innovare Academic Sciences Pvt Ltd. This is an open access article under the CC BY license (http://creativecommons. org/licenses/by/4. 0/) DOI: http://dx.doi.org/10.22159/ajpcr.2019.v12i2.28432

\section{INTRODUCTION}

Urinary incontinence is an involuntary leakage of urine which affects women of all ages, with prevalence increasing as the women ages. Although nulliparous women can have urinary incontinence, the incidence is higher in women who have given birth and increases with parity and also incidence increases in women with overweight [1]. The prevalence is $30-40 \%$ among young adult to middle-aged women and increases to $30-50 \%$ in older women. Urinary incontinence has traditionally been viewed as a social or hygienic problem, but it also has a major effect on quality of life and contributes to serious health problems, especially in older women [2].

Women can experience a spectrum of leakage ranging from loss of only drops or tablespoons or more depending on the severity of the urinary incontinence. The degree of incontinence a woman has is very subjective and personal to her [3]. Major complications of urinary incontinence are psychosocial problems which include embarrassment, negative self-perception, social isolation sleep disturbances, decreased quality of life, and restricted educational or leisure opportunities. Too many of them "live with" the condition too embarrassed to seek help or thinking that it is a "normal" part of aging and having children [3].

The first technique was described in 1948 by Kegel, who prescribed rapid voluntary contractions of the pelvic floor muscles. The author observed that $70 \%$ of the patients improved or were cured. However, even when provided with information on the anatomy and function of these muscles, $30 \%$ of the patients were unable to perform adequate voluntary. Use of vaginal cones to strengthen pelvic floor muscles was initially proposed by Plevnik in 1985 [4]. Vaginal cones are widely used in the treatment of incontinence in women and represent a simple and practical way to identify and strengthen the pelvic floor muscles.
When inserted into the vagina, it stimulates learning of contraction of the pelvic floor muscles by retaining cones with increasing weights. Thus, reflex contractions or voluntary muscles to prevent the sliding of the cone out, promote the recruitment of pubococcygeous muscles, maximize gain of muscle strength, and decrease the urine losses.

Vaginal cones are specially designed medical device which is inserted into the vagina and held in situ by contractions of the pelvic floor muscles. Vaginal cone is a non-invasive effective mode of treatment in patients with urinary incontinence.

Oblasser et al. stated that vaginal cone therapy with pelvic floor muscle training enhances the muscle performance and thereby prevent or treat urinary incontinence [5].

Women suffer from urinary incontinence nearly half of the life shells. Stress urinary incontinence occurs most often in young adult females, middle-aged women suffer from mixed incontinence, and older women suffer from urge incontinence. During the investigator's clinical experiences had noticed many women who failed to report the problem of urinary incontinence due to feeling ashamed, sad, and loneliness leading to decreased self-esteem and increase in anxiety. Most of the women were not willing to seek medical attention for this condition. This leads to an increasing alarm to treat urinary incontinence among women. The researcher has taken a step ahead to create awareness regarding urinary incontinence and reduce the level of urinary continence using vaginal cones.

The purpose of the study is (1) to assess the level of urinary incontinence in the experimental and control group, (2) to assess the effectiveness of vaginal cone therapy on urinary incontinence in the experimental group and control group, and (3) to associate the post-test level of 
urinary incontinence with the selected demographic variables among women in the experimental group.

\section{METHODS}

A quantitative approach with quasi-experimental research design [6,7] wasused to conduct the study in Obstetrics and Gynaecology Department both in the Outpatient and Inpatient Departments of Saveetha Medical College Hospital, Thandalam, Chennai, which is a super specialty hospital. The data were collected using a convenience sampling technique from 60 women with urinary incontinence. The inclusion criteria for the samples are women both multiparous and nulliparous women with urinary incontinence, who had undergone normal vaginal delivery and cesarean section with age between 30 and 70 years, who had delivered 2 months before, postmenopausal pelvic organ prolapse Stage I and II, slight and moderate urinary incontinence, who were available at the time of data collection, willing to participate in the present study and who understand Tamil/English. The exclusion criteria for the samples were women who had under treatment for urinary incontinence, with a history of urinary tract infection, with a history of neurological disease, pregnant women, with intrauterine devices, with reproductive tract infection, and with psychiatric illness. The data were collected from $8^{\text {th }}$ December 2017 to $31^{\text {st }}$ December 2017 after obtaining ethical clearance from the Institutional Ethical Committee of Saveetha Institute of Medical Science and Technology. The purpose of the study was explained to the samples and written informed consent was obtained from them. The demographic data were collected using a structured interview questionnaire, and the level of stress incontinence was assessed using the questionnaire for urinary incontinence diagnosis (QUID) which was developed by Catherine [8]. Before the treatment, the patient was taught pelvic floor muscles tightening. First cone No.1 was covered with male condom and inserted gently into the vagina in dorsal recumbent position with the cone tip and the nylon cord pointing downward. If the first cone sensation was not felt by the women cone number 2 was then inserted, the replacements were continued with consecutively heavier weights until a sensation of loss was perceived. The woman was then instructed to walk and not to contract her pelvic floor muscular for $1 \mathrm{~min}$ and to report any sensation of losing the device. The subject was instructed to walk for $15 \mathrm{~min}$ daily with the cone in her vagina without voluntary contracting her pelvic floor muscles. This procedure was continued for 2 weeks. Posttest was conducted after 2 weeks to assess urinary incontinence using QUID [8].The data were analyzed using descriptive and inferential statistics. The sample characteristics were described using frequency and percentage. Pearson's correlation coefficient $[9,10]$ was used to assess the effectiveness of vaginal cone therapy among women with urinary incontinence in the experimental group. Chi-square $[9,10]$ was used to associates post-test level of urinary incontinence with the selected demographic variables.

\section{RESULTS}

\section{Section A: Sample characteristics}

Among 60 samples, 30 belong to experimental group, majority $12(40 \%)$ were in the age group of 50-59 years, $19(63.33 \%)$ had no formal education, 21 (70\%) belonged to joint family, 17 (56.67\%) were doing primary sector type of occupation, 11 (36.67\%) women were multiparous, 29 (96.67\%) had normal vaginal delivery, 18 (60\%) had undergone institutional delivery, 25 (83.33\%) had undergone delivery 10 years back, $8(26.67 \%)$ attained menopause at the age of $41-45$ years, $15(50 \%)$ were in the stage of postmenopause, $9(30 \%)$ had no pelvic organ prolapse, $3(10 \%)$ had urinary incontinence before hysterectomy, $16(53.33 \%)$ had a body mass index (BMI) of 25-29.9 (overweight), and $15(50 \%)$ experiencing urinary incontinence for $<1$ year. Remaining 30 samples belong to control group, majority $15(50 \%)$ were in the age group of 50-59 years, 22 (73.33\%) had no formal education, 15 (50\%) belonged to joint and nuclear family, respectively, 17 (56.67\%) were homemakers, 19 (63.33\%) were multiparous, 27 (90\%) had normal vaginal delivery, $18(60 \%)$ had undergone institutional delivery, $24(80 \%)$ had undergone delivery 10 years back, 12 (40\%) attained menopause at the age of 35-40 years, $21(70 \%)$ were in the stage of postmenopause, $2(6.67 \%)$ had 0 degree of pelvic organ prolapse, $2(6.7 \%)$ had urinary incontinence post hysterectomy, 18 (60\%) had a BMI of 25-29.9 (overweight), and 17 (56.67\%) experiencing urinary incontinence for $1-5$ years.

\section{Section B: Level of urinary incontinence among women}

The prevalence of urinary incontinence in experimental group 26 women had moderate level of urinary incontinence and 4 women had slight urinary incontinence whereas in control group 24 women had moderate level of urinary incontinence and 6 women had slight urinary incontinence [Table 1].

Section C: Effectiveness of vaginal cone therapy on urinary incontinence among women in the experimental and control group Vaginal cone therapy which is administered to the women with urinary incontinence in the experimental group had a significant reduction in the level of urinary incontinence than the women in the control group at the level of $\mathrm{p}<0.05$ level [Table 2].

Section D: Association of post-test level of urinary incontinence with selected demographic variables among women in the experimental group

Parity had shown statistically significant association with post-test level of urinary incontinence among women in the experimental group at $\mathrm{p}<0.05$ level and the other variables had not shown statistical significance [Table 3].

\section{DISCUSSION}

The present study findings depict that in experimental group 26 women had a moderate level of urinary incontinence and 4 women had slight urinary incontinence whereas in control group 24 women had moderate level of urinary incontinence and 6 women had slight urinary incontinence [Fig. 1]. The present study finding is supported by Kilic who conducted a study to determine the incidence and risk factors of urinary incontinence in women visiting family health centers in Turkey. The study results determined that most of the women had urinary incontinence, but only a few consulted the physician due to negative self-perception [11]. Hence, it was concluded from the above studies that the prevalence of moderate urinary incontinence is more when compared to that of slight urinary incontinence. Hence, there is a need for non-invasive treatment like vaginal cone therapy which can be encouraged and practiced to treat urinary incontinence at the minimal level.

Table 1: Frequency and percentage distribution of level of urinary incontinence among women in the experimental group and control group

\begin{tabular}{|c|c|c|}
\hline \multirow[t]{3}{*}{$\begin{array}{l}\text { Level of urinary } \\
\text { incontinence }\end{array}$} & $\begin{array}{l}\text { Experimental } \\
\text { group }\end{array}$ & $\begin{array}{l}\text { Control } \\
\text { group }\end{array}$ \\
\hline & Pre-test & Pre-test \\
\hline & n (\%) & n (\%) \\
\hline Slight urinary incontinence & $4(13.33)$ & $6(20.0)$ \\
\hline Moderate urinary incontinence & $26(86.67)$ & $24(80.0)$ \\
\hline
\end{tabular}

$\mathrm{N}=60(30+30)$

Table 2: Effectiveness of vaginal cone therapy on urinary incontinence among women in the experimental and control group

\begin{tabular}{lll}
\hline Level of urinary incontinence & Mean \pm SD & Unpaired ' $t$ ' Value \\
\hline Experimental group & $3.23 \pm 1.41$ & $\mathrm{t}=2.353$ \\
Control group & $4.10 \pm 1.45$ & $\mathrm{p}=0.022, \mathrm{~S}^{*}$ \\
\hline$* \mathrm{p}<0.05$ s. Significant $\mathrm{n}=60(30+30)$ & $\mathrm{SD} \cdot$ Standard deviation
\end{tabular}


Table 3: Association of post-test level of urinary incontinence with selected demographic variables among women in the experimental group

\begin{tabular}{|c|c|c|c|}
\hline \multirow[t]{2}{*}{ Demographic Variables } & \multirow{2}{*}{$\begin{array}{l}\text { Slight urinary incontinence } \\
\text { n (\%) }\end{array}$} & \multirow{2}{*}{$\begin{array}{l}\text { Moderate urinary incontinence } \\
\text { n (\%) }\end{array}$} & \multirow[t]{2}{*}{ Chi-Square Value } \\
\hline & & & \\
\hline Parity & & & $\chi^{2}=8.030$ \\
\hline 1 & $0(0)$ & 5 (16.7) & d.f $=3$ \\
\hline 2 & 7 (23.3) & $4(13.3)$ & $\mathrm{p}=0.045$ \\
\hline 3 & 5 (16.7) & $6(20.0)$ & $S^{*}$ \\
\hline 4 & $0(0)$ & $3(10.0)$ & \\
\hline
\end{tabular}

${ }^{*} \mathrm{p}<0.05$, S: Significant $\mathrm{n}=30$

In the present study, vaginal cone therapy which is administered to the women with urinary incontinence in the experimental group had a significant reduction in the level of urinary incontinence than the women in the control group. The level of urinary incontinence shows reduction than the control group at the level of $\mathrm{p}<0.05$ level [Fig. 2]. This reveals that vaginal cone therapy was highly significant in the experimental group because pelvic muscle strength had improved and allows the patient to increase the physiological consciousness and promotes the muscle tone after the use of a vaginal cone. These findings were also supported by Ong et al., who determined the use of vibrance kegel device with pelvic floor muscle exercise for stress urinary incontinence through randomized controlled trial in Malaysia, 43 samples. The results showed that using the vibrance kegel device resulted in significant early improvement in stress urinary incontinence scores, and pelvic muscle strength had improved significantly by the end of the study [12]. Thus, they concluded that the vaginal cone therapy strengthens the pelvic floor muscles and improves the bladder control thereby urinary incontinence is reduced/treated. Hence, the research hypothesis was accepted.

In the present study, there was a statistical significant association in parity with the post-test level of urinary incontinence among women in the experimental group at $p<0.05$ level and the other variables had not shown statistical significance. Pregnancy and childbirth stretches, weakens and injures the pelvic floor muscles which increase the risk of urinary incontinence in women with high parity. Vaginal cone therapy promotes the sensorimotor biofeedback which increases the muscle contraction and improves the urethral closure and maintains the continence. Thus, the present study was an attempt to address important issues related to urinary incontinence among women. Hence, it is evident that vaginal cone therapy reduces the level of urinary incontinence among women. More extensive studies are required to be encouraged to be done in this aspect.

The present study was also supported by Sumathi who determined the effectiveness of pelvic floor rehabilitation with a vaginal cone on continence and quality of life among women with stress urinary incontinence. The research design adopted for the study was randomized control trial done with 250 samples. The setting for the study was Obstetrics and Gynaecology Outpatient Department of Sri Ramachandra Hospital. The pre-test results of the study show pretest $2(1.6 \%)$ of the women in the study group and $5(4 \%)$ of the women in the control group had a mild level of UTS, 123 (98.4\%) of the women in the study group, and 120 (96\%) of women in the control group had a moderate level of UTS. The post-test results of the study show association with all the obstetrical variables such as parity, number of abortions, birth weight of the baby, and place of delivery at level of $\mathrm{p}<0.001$ [13]. Akram et al. conducted a study on extractive spectrophotometric determination of some antimuscarinic antagonist in tablet formulations using Eriochrome Cyanine R the study results suggested that oxybutynin, solifenacin, tolterodine, and fesoterodine used for quality control and routine analysis where time, cost-effectiveness and high specificity of the analytical technique are of great importance. The works by relaxing the involuntary detrusor muscle in the wall of the bladder by blocking muscarinic/cholinergic receptors present on the surface of the muscle cells and thus prevents

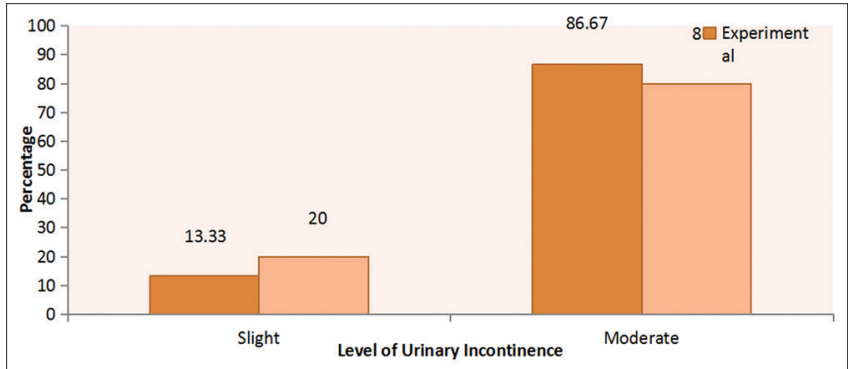

Fig. 1: Percentage distribution of the level of urinary incontinence among women in the experimental group and control group

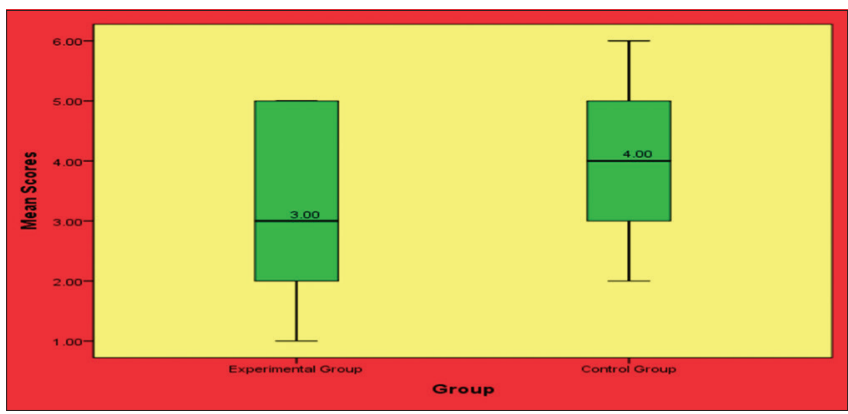

Fig. 2: Effectiveness of vaginal cone therapy on urinary incontinence among women in the experimental and control group

acetylcholine from acting on these receptors [14]. The study is also supported by Pankaj and Bala had conducted a study to assess the pathophysiology, mechanism and its management of overactive bladder syndrome. The results of the review provide information of $\mathrm{OAB}$ and its different therapies such as behavioral modification, drug therapy, and the combination of both. If the symptoms are not managed by these treatments, then invasive therapies such as botulinum toxin $A$ injection, neuromodulator implants, and augmentation cystoplasty may be exploited for complete control and balancing the efficacy and complications or side effects of invasive therapies [15].

\section{CONCLUSION}

Vaginal cone therapy is an effective non-pharmacological method and cost-effective method to treat female urinary incontinence. The selected women became familiar and comfortable to practice vaginal cone. From the results of the study, it was concluded that vaginal cone therapy had no side effects and it is an easy and comfortable method which can be practiced for a long time to treat urinary incontinence.

\section{ACKNOWLEDGMENT}

We would like to extend our gratitude to the authorities of Saveetha College of Nursing and Saveetha Medical College Hospital. 


\section{AUTHORS' CONTRIBUTION}

All the authors actively participated in the work of the study. All authors read and approved the final manuscript.

\section{CONFLICTS OF INTEREST}

The authors declare no conflicts of interest.

\section{REFERENCES}

1. Perry L, Alden C. Maternity Women's Health. St. Louis: Elsevier Publishers; 2012. p. 234-5.

2. Brown D, Edwards H, Buckley T. Lewis's Medical-Surgical Nursing: Assessment and Management of Clinical Problems. New Delhi: Elsevier Publishers; 2015. p. 761-5.

3. Kathleen K. A Monograph from the Urology Care Foundations: Stress Urinary Incontinence. Maryland: American Urology Association; 2011.

4. Haddad JM, Ribeiro RM, Bernardo WM, Abrão MS, Baracat EC. Vaginal cone use in passive and active phases in patients with stress urinary incontinence. Clinics (Sao Paulo) 2011;66:785-91

5. Oblasser C, Christie J, McCourt C. Vaginal cones or balls to improve pelvic floor muscle performance and urinary continence in women postpartum: A quantitative systematic review. Midwifery 2015;31:1017-25.

6. Polit DF, Hungler BP. Nursing Research Principles and Methods.
Philadelphia, PA; Jaypee Publications; 1999. p. 103.

7. Hungler BP, Denise FP. Nursing Research. Philadelphia, PA: Lippincott Company; 1999. p. 112-3

8. Catherine B. The questionnaire for urinary incontinence diagnosis (QUID). J Urol 2010;181:86-7.

9. Gupta SG, Kapoor V. Fundamentals of Mathematical Statistics. New Delhi: Jaypee Publishers; 1990. p. 210.

10. Gurumani N. An Introduction to Bio Statistics. Chennai: MJP Publishers; 2005. p. 98.

11. Kılıç M. Incidence and risk factors of urinary incontinence in women visiting family health centers. Springerplus 2016;5:1331.

12. Ong TA, Khong SY, Ng KL, Ting JR, Kamal N, Yeoh WS, et al. Using the vibrance kegel device with pelvic floor muscle exercise for stress urinary incontinence: A Randomized controlled pilot study. Urology 2015;86:487-91.

13. Sumathi G. Effectiveness of pelvic floor rehabilitation with vaginal cone on continence and quality of life among women with stress urinary incontinence. Shodhganga 2015;2015:216-29.

14. Akram E, Monuir S, Nora S. Extractive-spectro-photometric determination of some antimuscarinic antagonist in tablet formulations using eriochrome cyanine R. Int J Pharm Pharm Sci 2018;10:22-8.

15. Pankaj M, Bala P. Pathophysiology, mechanism and its management of overactive bladder syndrome-review. Int J Pharm Pharm Sci 2018;10:1-3. 